\title{
Sweden likely winner for neutron source
}

Sweden is claiming victory in a long-running battle to host Europe's next-generation neutronscience facility.

The European Spallation Source (ESS), a $€ 1$.4-billion (US\$2-billion) neutron facility, will be built in Sweden, according to officials there. The site, near the city of Lund, beat rival locations in Spain and Hungary.

Seven nations out of twelve potential backers voted for the Lund site. Only one, Portugal, voted for the Spanish location, according to Colin Carlile, the director of ESS Scandinavia, the organization in charge of the Swedish bid.

But the other candidate host nations are unwilling to concede defeat. The 28 May vote was simply an "opinion", says Lázló Rosta, the project director for ESS Hungary and a scientist at the Budapest Neutron Center. "There is sort of a Swedish advantage, but there is not a final decision," he says.

Spallation neutron sources, which accelerate protons onto a heavy metal target to produce neutrons, can create higher-powered neutron beams using less energy than conventional production methods using reactors.

The ESS has been on European neutron scientists' drawing board for the best part of a decade. Germany had originally offered to host the site, but later withdrew after the project was not endorsed by the nation's science council (see Nature 418, 262; 2002). Since then, it has been in search of a home. In an unusual move, Spain and Hungary had promised to endorse each other's sites if either was chosen over Sweden.

But Sweden seems to have won. Carlile says that under the terms offered to the research ministers, Sweden, together with its Nordic and Baltic partners, will pay $50 \%$ of the project's construction costs. The team is looking for at least $35 \%$ of the funding to come from other nations, such as the United Kingdom, France and Germany. The remainder, up to $15 \%$, will be paid for with a bridging loan from the Swedish government.

Rosta says that he believes there may be a way to include the Hungarian and Spanish proposals in the Swedish bid. The idea, he says, would be to develop the ESS accelerator in Spain and the instrumentation in Hungary. Alternatively, he says, one of the two sites could play host to a smaller spallation neutron source. "We would like to see the three sides arrive at a win-win situation," he says.

Carlile says that he hopes an agreement on cost sharing will come within months, so that construction can begin in 2012. That schedule would see the ESS delivering its first neutrons between 2018 and 2019.

Geoff Brumfiel 